\title{
Review
}

Birgit Arabin*, Lars Hellmeyer, Johanna Maul and Gerlinde A.S. Metz

\section{Awareness of maternal stress, consequences for the offspring and the need for early interventions to increase stress resilience}

https://doi.org/10.1515/jpm-2021-0323

Received June 28, 2021; accepted June 29, 2021;

published online September 6, 2021

\begin{abstract}
Experimental and clinical studies suggest that prenatal experiences may influence health trajectories up to adulthood and high age. According to the hypothesis of developmental origins of health and disease exposure of pregnant women to stress, nutritional challenges, infection, violence, or war may "program" risks for diseases in later life. Stress and anxieties can exist or be provoked in parents after fertility treatment, after information or diagnosis of fetal abnormalities and demand simultaneous caring concepts to support the parents. In vulnerable groups, it is therefore important to increase the stress resilience to avoid harmful consequences for the growing child. "Enriched environment" defines a key paradigm to decipher how interactions between genes and environment change the structure and function of the brain. The regulation of the fetal hippocampal neurogenesis and morphology during pregnancy is one example of this complex interaction. Animal experiments have demonstrated that an enriched environment can revert consequences of stress in the offspring during critical periods of brain plasticity. Epigenetic markers of stress or wellbeing during pregnancy might even be diagnosed by fragments of placental DNA in the maternal circulation that show characteristic methylation patterns. The development of fetal senses further illustrates how external stimulation may impact individual preferences. Here, we therefore not
\end{abstract}

\footnotetext{
*Corresponding author: Birgit Arabin, MD, PhD, Clara Angela Foundation, Berlin, Germany; and Department of Obstetrics, Charité, Humboldt University Berlin, Augustenburger Platz, 13353 Berlin, Germany, E-mail: bine.clara.angela@gmail.com Lars Hellmeyer, Clara Angela Foundation, Berlin, Germany; and Vivantes Klinikum im Friedrichshain, Berlin, Germany Johanna Maul, Clara Angela Foundation, Berlin, Germany Gerlinde A.S. Metz, Clara Angela Foundation, Berlin, Germany; and Canadian Centre for Behavioural Neuroscience, University of Lethbridge, Lethbridge, AB, Canada
}

only discuss how maternal stress influences cognitive development and resilience, but also design possibilities of non-invasive interventions for both mothers and children summarized and evaluated in the light of their potential to improve the health of future generations.

Keywords: creative interventions to support stress resilience; fetal programming; maternal stress; prevention of psychiatric diseases.

\section{Introduction}

Aristotle already mentioned that our sensory development starts antenatally to be prepared for the challenges of extrauterine life. He postulated epigenetic processes and compared the influence of the mother's environment with how the earth supports the development of plants [1]. Therefore, in ancient times it was recommended that pregnant women should live in a stimulating environment and avoid harmful influences.

It was not until the 20th century that new biophysical tools allowed to directly approach the fetus and to observe early fetal reactions towards maternal and external stimuli. As a pioneer, Prechtl described the continuous development from prenatal to postnatal life [2]. The care of pregnant women became a matter of public health concerns with regular controls of pregnant women; it was then that maternal-fetal medicine became a subspecialty of its own. Epigenetic studies of fetal programming such as proposed by the concept of developmental origins of health and disease (DOHaD) have demonstrated a harmful impact of maternal undernutrition on cardiovascular, metabolic, and mental health in the offspring up to adulthood [3-5]. It was recognized that not only prenatal or early postnatal exposure to undernutrition, but also maternal stress may reprogram brain development and increase risk of behavioral and neurological disorders later in life. Long-term follow up of humans whose mothers had been tested positive for maternal stress, anxiety, or depression even 
from the first trimester onwards demonstrated delayed cognitive development and impaired mental health in later life [6].

Unfortunately, pregnancy assessments usually do not involve screening tools for maternal stress, anxiety depression, although validated questionnaires such as the perceived stress scale (PSS), the stress trait anxiety inventory (STAI) or the Edinburgh postnatal depression scale (EPDS) readily exist and could be easily implemented. Maternal-fetal specialists have rather concentrated on the detection of risks of chromosomal abnormalities, fetal abnormalities pregnancy complications, or emergencies and sometimes even induce maternal stress instead of recognizing their chances to prevent the fatal consequences on the fetus up to adult life. The fetal brain seems to be a sensitive target for maternal stress effects because the differentiation of major brain structures occurs during prenatal life [7]. It is speculated that $17 \%$ of the variance of later psychological disease in adulthood are caused prenatally [8]. In pregnancies after artificial reproductive techniques, with chromosomal abnormalities or congenital heart defects (CHD), when pregnant women are exposed to natural disasters, the COVID-19 pandemic, social deprivation, violence, or war, maternal stress levels are even more increased and therefore initiate a vicious circle for the offspring [9-12] (Figure 1).

Interventions that counteract the transgenerational transmission of stress have not yet been developed although they would be desperately needed mainly in identified focus groups. Work in animal models has proven that the effects of artificially induced transgenerational maternal stress can be "reversed" by increasing stress resilience. Many of these interventions follow the model of "environmental enrichment" (EE) and have been developed in rats and mice [13]. In this review we summarize experimental and clinical findings related to transgenerational stress, sensory and cognitive development and discuss their relevance for future pregnancy care.

\section{Stress factors of pregnancy and fetal programming}

Maternal well-being determines fetal and postnatal cognitive and psychosocial development. Numerous clinical studies have summarized the consequences of high anxiety and stress levels in pregnant women on the mental health of their offspring, but unfortunately did not translate into screening or care concepts [6, 14-17]. Meanwhile, only one European region has introduced a screening concept for maternal stress and the risks for the offspring [18]. Recent epigenetic studies have shown that early deviations in temperament and cognitive development were initial indicators of previous maternal stress. Maternal stress and anxiety or depression can persist or even increase after birth and be associated with a negative attitude towards parenthood [19]. This may have an additional impact on the offspring, which is modified by the genetic disposition or additional challenges in later life. Each stress factor can shorten the telomere length, a prominent marker of biological aging, in women by 35 base pairs [20].

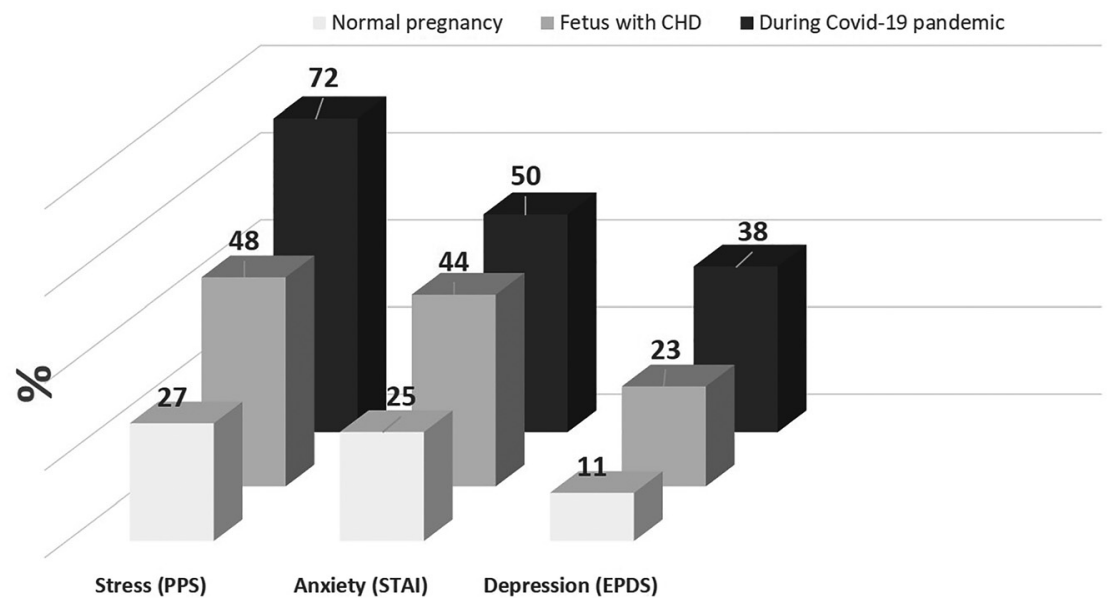

Figure 1: Maternal stress measured by the perceived stress scale (PSS), anxiety measured by the stress trait anxiety inventory (STAI) or depression measured by the Edinburgh postnatal depression scale (EPDS) as it is distributed in normal pregnancies (left columns), after the diagnosis of a congenital heart defect (CHD) (centered columns) and during COVID-19 (right columns).

Modified according to ref. [10] and unpublished data from a Zoom lecture of Catherine Limperopoulos from the Center for the developing brain children's' health system Washington, 2020. 
During pregnancy, stress factors may increase proinflammatory markers and thereby even shorten telomere length in newborns [21]. It is estimated that globally, 250 million children (43\%) under five years are at high risk of not reaching their physical, intellectual, and creative potential to become healthy and happy adults [14].

Acute symptoms of maternal stress are not uncommon during pregnancy and activate the "stress axis" (HPA axis) from the hypothalamus to the pituitary gland and to the adrenal cortex in both mothers and children. The fetal brain is thought to cope better with acute challenges, although in rats acute maternal stress impacted psychomotor functions in terms of motivational changes in the central-object variations of exploratory tasks in the offspring [22]. Brief maternal stress can cause sudden changes in uterine blood flow, fetal heart rate (FHR) and fetal movement patterns. The effects of stress on the HPA axis depend on age, gender, and duration of the stressor. Short-term stress also affects the HPA axis, corticosteroid levels, psychomotor function, and exploratory behavior in offspring in ref. [22].

Chronic stress can disrupt basic physiological and metabolic functions and adversely affect health. Such chronic stress situations can be simulated repeatedly over a long period of time in different generations, e.g., through social isolation. Chronic stress predisposes fetuses to changes in growth, metabolism, structure, and function of their brains and later in life even life expectancy [23-25]. Children of mothers with anxiety symptoms show a doubling of behavioral problems compared to a normal population [14]. But not only experience within a single lifetime, but also ancestral experience affects health trajectories and chances of successful aging or disease incidence by formation of an epigenetic memory [26]. Without prevention it can take too much time for interventions of social support and sensual stimulation ("EE") to reverse the negative consequences. Mediators are mainly cortisol, but also catecholamines, cytokines, serotonin/tryptophan, oxygen radicals, and finally the microbiome [27] (Figure 2). Epigenetic mechanisms are the link in this complex process. Biological indicators could help to identify risks and initiate early stimulation programs. Finally, even fetuses themselves are thought to stimulate the maternal sympathetic system that prepares mothers for their care through fetal movements [17].

Prenatal stress experience increases the sensitivity of the developing organism to postnatal influences [28] and explains the different outcome by a pre-existing context [29]. This may offer important opportunities for early intervention strategies.

Low birth weight also programs future mental health and was shown to be associated with hostility in later life [30]. Studies of the Dutch Hunger Winter showed that children of pregnant women who were starving during their first trimester (and certainly exposed to stress) showed increased rates of schizophrenia, depression, or inadequate stress responses in later life [31]. Since the association between birth weight and ADHD has not been confirmed in selected communities, it is likely that maternal care can break this link [32, 33]. Gestational age and birth weight explain only $1 \%$ of the variance in emotional behavioral abnormalities, but maternal stress

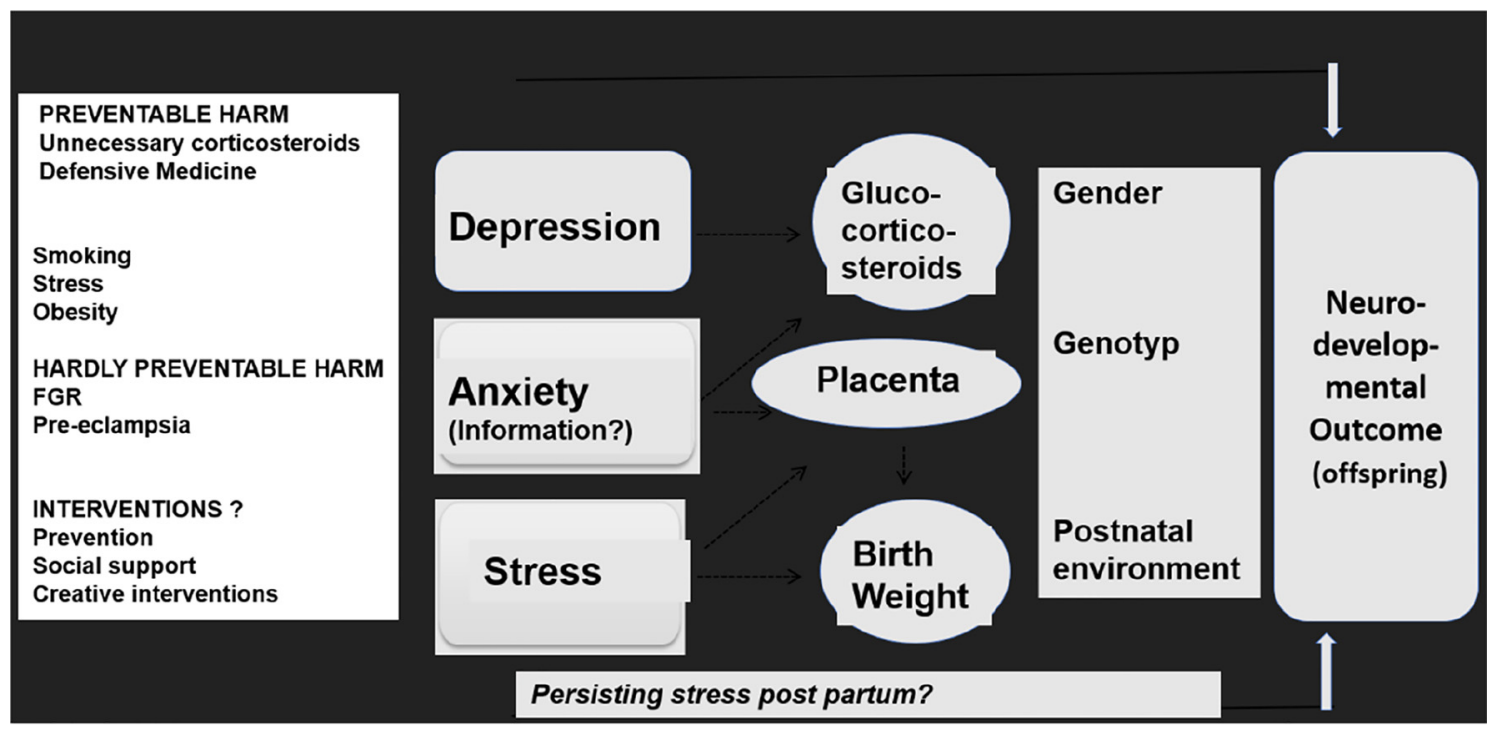

Figure 2: Main mediators of maternal stress via the placenta to the fetus.

Modified according to ref. [14]. 
explains $17 \%$ mainly when the socioeconomic status is also considered [14]. Intensified maternal care can modify the outcome in groups affected by fetal growth restriction (FGR) [34]. Parental care compensates for hippocampal hypofunction in low birth weight children, thereby supporting the effective regulation of the stress axis [34]. A high socioeconomic status also reduces the effects of FGR on mental health in children [35], while a low socioeconomic status increases the negative effect of glucocorticoids and stress on long-term memory [23]. In all populations, the duration of breastfeeding promotes cognitive development even more significantly in children with FGR as compared to children with normal birth weight $[36,37]$.

Even chronic exposure to modern media or death of a loved one is associated with low birth weight $[38,39]$. Endocrine factors such as $\beta$-human chorionic gonadotropin ( $\beta$-HCG) or progesterone are possible mediators of sex-specific effects. In a multivariable regression model, an increase in maternal progesterone of $1 \mathrm{ng} / \mathrm{ml}$ in the first trimester increased girls' birth weight by $10.17 \mathrm{~g}(95 \% \mathrm{CI}$ 2.03-18.31); in male offspring, stress during pregnancy caused growth retardation independent of progesterone concentrations [40].

\section{The concept of environmental enrichment}

The early development of animal and human offspring is determined by unchangeable (genetic) and dynamic (epigenetic) factors. From conception to old age, experiences and activities cause continuous anatomical and functional changes in our brain both in a negative and positive way. The EE paradigm was introduced by a Canadian neuropsychologist Donald Hebb in the 1940s to understand the role of experience on brain development. He compared rats under standardized laboratory conditions with rats raised like pets in his own home showing improved memory performance [41]. Mark Rosenzweig defined EE as a combination of inanimate and/or social stimuli [13]. The experimental design has been modified in rats or mice when animals were raised in multimodal laboratory conditions that included toys. tunnels, running wheels, ladders or larger cage space (Figure 3) [42]. Thus, the animals experience a greater range of sensory, cognitive and motor stimuli compared to standard housing conditions [43]. Neuroanatomical studies in rats showed higher brain weights, stronger cross-linking of dendrites [44] and an increase in brain-derived neurotrophic factor (BDNF) expression responsible for facilitated neuroplasticity in EE $[45,46]$. It was also shown that EE causes a higher degree of histone acetylation at the BDNF gene [47-49]. These mechanisms explain how EE promotes the development of the fetal brain, later counteracting premature aging, and supporting lifelong learning and stress resistance.

Animal studies can unravel the complex relationships of unfolding our genetic potential up to old age. Early experiences during developmental periods of high plasticity modify our personality. Accordingly, in pregnant mice, maternal EE accelerated cell migration in the temporal lobe [50], cell proliferation in the hippocampus [51] and earlier opening of the eyes in the offspring [52]. Neurological reflexes and motor coordination are milestones of neuromotor development [53]. Reflexes on auditory and sensorimotor stimuli developed two days earlier in the offspring of stimulated pregnant rats as compared to offspring of pregnant rats under standard conditions $(p<0.05)$. They also showed better motor functions (e.g., to bend or stand upright) up to 3 weeks after birth $(\mathrm{p}<0.05)$.

Epigenetic mechanisms respond to environmental changes transmitting transgenerational stress by altering gene expression $[54,55]$. This can occur via paternal and maternal transmission. Thus, the experience of previous generations may favor adaptations in behavior and physiology in their offspring that ensure their survival. However, stress adaptation can also harm other important
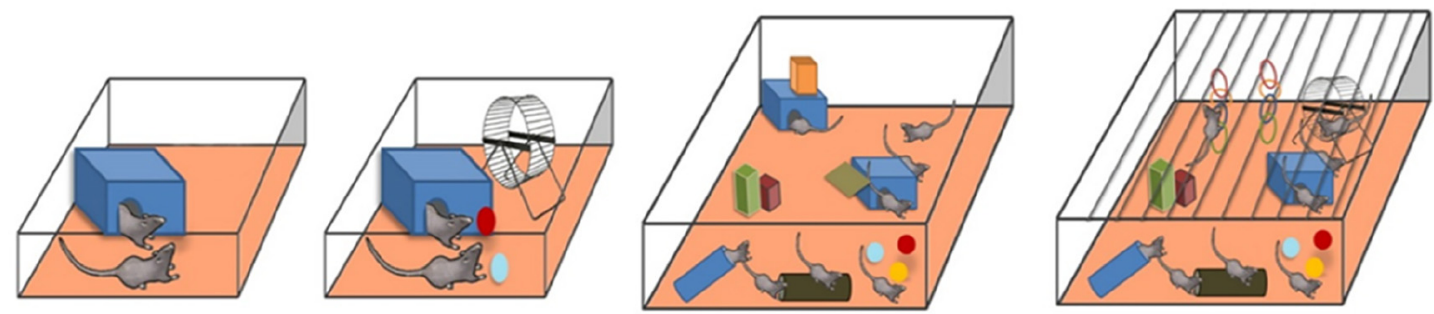

Figure 3: Schematic overview of "environmental enrichments" with variable components and social dynamics in animals. Modified according to ref. [111]. 
functions: Stress in male rats during spermatogenesis can cause DNA methylation passed on to the next generation (F1), leading to reduced stress reactivity and impaired motor development $[56,57]$. Since exposure to stress from previous generations is irreversible and hard to control, there is considerable interest in the extent to which EE can reduce or reverse such risks. Breeding several generations in animal models can provide more feasible and practical approaches than studies in humans.

Recently developed animal models can distinguish between stress in only one preceding generation ("transgenerational") or cumulative stress ("multigenerational") in several preceding generations $[58,59]$. In experimental designs, the effects on the offspring of both situations can then be compared with those of control groups that grew up with and without EE. It has been shown that repeated or cumulative stress can lead to limited stress resilience or adaptation at the expense of premature biological aging with a high risk of chronic disease [60,61]. Overall, psychosocial and/or physical stress of varying duration and the EE interventions (e.g. stimulation of motor skills with or without social factors) may differ within the models [60]. An example of effective therapy with EE is the study of neuromotor function of the offspring in rat models after different stress of previous generations [58]. Animals were observed walking over a ladder (Figure 4). With increasing ancestral stress, the number of unsuccessful attempts by front or hind legs to reach the ladder rungs increased. The results were reversed after EE, so that the animals with originally high risk performed better than animals from the control group with EE (Figure 4 right). Interestingly, female animals react more positively to social EE components by the release of oxytocin which serves as a "cuddle hormone" supporting bonding and social contacts. It also has a stress-reducing effect, increases BDNF expression and reduces aging processes [62]. The studies suggest that social networks or creative interventions can promote neurodevelopment into adulthood.

\section{Sensory development and previous intervention models}

The fetus not only responds to maternal stress or wellbeing, the increasing integrity of the sensory system allows to become aware of an outside world, whereby stimuli are first projected to subcortical areas and associated with behavioral patterns via neurons [63].

Already in the sixth week of pregnancy (SSW) skin receptors develop in the mouth region and are found on the entire skin surface until the 20th week of pregnancy. In 1952, Hooker described reactions to touch after therapeutic abortions at the end of the first trimester [64]. By this time, synapses develop in the posterior horn of the spinal cord, into which the nerve endings lead. Between 20 and 24 weeks of gestation, switch points and fibers from the thalamus to the cerebrum are formed, which are prerequisite for the experience of touch and pain [65]. Fetuses react to pain stimuli during invasive procedures [66]. After surgery on the fetus itself, a 590\% increase in ß-endorphin and an $183 \%$ increase in cortisol was measured; the

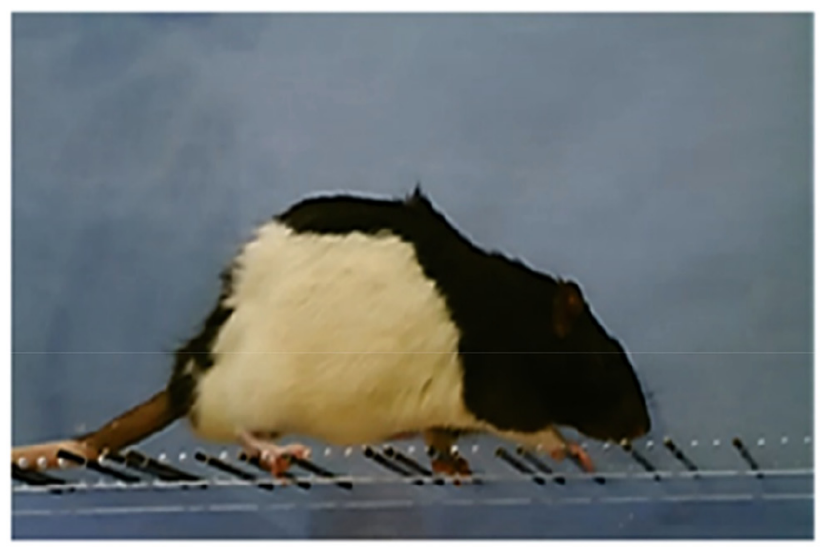

Standard
Enrichment

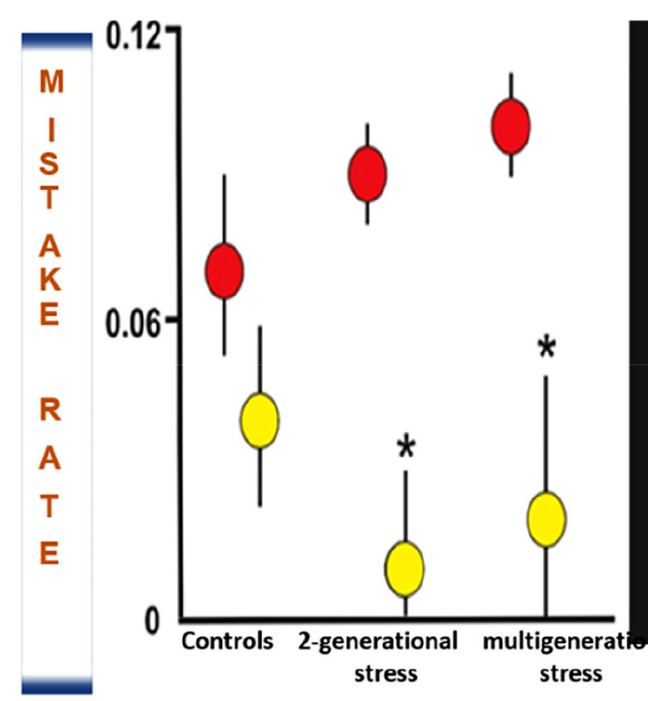

Figure 4: Rat crossing the ladder, mean number of wrong attempts of the rear extremities as compared to the total number of steps without (red) and with (yellow) EE.

*Significance of $E E$ p $<0.05$. Values represent mean value $\pm S D$, according to ref. [53]. 
increase in norepinephrine was associated with the duration of the procedure [67]. Reactions to the touch of a cotwin were observed from 8 to 10 gestational weeks onwards in mono-amniotic twin gestations. Before $16 \mathrm{SSW}$, male fetuses showed faster but less complex reactions than female or mixed couples [68], suggesting early influences of testosterone [69]. Somatosensory evoked potentials were described in preterm infants from 28 weeks onwards prerequisite for the memory of sensory sensations [70, 71]. Preand postnatal experiences are not necessarily comparable. Haptonomy where parents are introduced to contact their children prenatally by touch has never poorly evaluated. However postnatally premature babies have lower rates of infection and mortality when the kangaroo procedure was applied which also promoted breastfeeding rates and skull growth [72].

The outer ear is visible from the 10 gestational weeks onwards. Bones of the middle ear have already the same size as in adulthood at 18 weeks. The organ of Corti in the inner ear starts to develop at 10 gestational weeks and contains sensory and supporting cells including inner and outer hair cells with synapto- and ciliogenesis. At around 20 weeks, the morphology corresponds to the onset of cochlear function [60]. Cells of the auditory nerve enter the brainstem and pass eight synapses before entering the cerebrum. Many auditory abilities are attributable to subcortical processing.

The intrauterine world is determined by frequencies $<500 \mathrm{~Hz}$ and sound intensities from vascular pulsations, maternal respiration, or digestion (imprinting effect) of up to $90 \mathrm{~dB}$. Music and voices are audible at a volume of $8-12 \mathrm{~dB}$, with male voices at $125 \mathrm{~Hz}$ at $125 \mathrm{~Hz}$ at $125 \mathrm{~Hz}$ being less absorbent and female voices at around $220 \mathrm{~Hz}$ more distinguishable. When fetuses were exposed to sounds from 100 to $3,000 \mathrm{~Hz}$, initial reactions were seen at 22 weeks and $500 \mathrm{~Hz}$, at 27 weeks and $100-500 \mathrm{~Hz}$, and from 31 weeks on at 1,000-3,000 $\mathrm{Hz}$ [73]. They can also be detected by changes in electric potentials to acoustic stimuli or stimulus-related neuromagnetic fields with decreasing latency of $300-150 \mathrm{~ms}$ from 34 weeks of gestation to term [74].

Short behavioral responses in terms of the fetal heart rate (FHR), fetal movements or eye blinking can be observed by ultrasound. Reactions are modified by fetal behavioral stages [75]. Repeated exposure to sound has been associated with fetal conditioning: Experiments in "habituation" show that the fetus can remember and compare sounds [76]. The memory exceeds the threshold of pre- to postnatal life [77] and shapes postnatal preferences. It has been proven that third trimester fetuses are familiar with their mother's language [78]: Newborns prefer to hear the mother's voice or the language or melodies spoken or sung by the mother which was demonstrated by sucking with a "sucky-dummy device" [79]. Sounds that resemble the intrauterine environment, but also music, encourage sucking and falling asleep of newborns [80, 81]. Pilot studies have also shown fetal behavioral changes when mothers listen to music with headphones only [82]. Whether fetuses are "enriched" more by direct exposure or maternal relaxation is difficult to distinguish when both are directly and simultaneously exposed to music after 22 weeks. In any case, music exposure during pregnancy promotes neuromotor skills in childhood [83] and stable behavior as compared to controls [83]. Prenatal musical experiences - mainly rhythmic elements - are still remembered after one year [84], although the time span of acoustic memory is shorter in newborns than in adults [85].

"Music is my first love, it will be my last". This song by John Miles still applies in different cultures, as a number of proto-rhythms seem to be of biological prenatal origin [86]. The maternal voice represents a continuity from pre- to postnatal life $[87,88]$. This relationship is "musical" since the child does not yet understand the meaning of language. Listening has an influence on voice formation, hence spectrographic images of the first cry of a newborn child are already similar to the patterns of the maternal voice [89]. Various devices are commercially available to expose fetuses to music programs, but we doubt that the music produced will reach the fetus, and the band to the mother is missing [90]. Lubetzki et al. [91] played Mozart music for premature babies between 32 and 37 weeks: As compared to a control group, energy consumption was reduced in those who listened to Mozart. In children with disabilities, music therapy was able to improve development, especially communicative skills [92]. Studies in adults support the hypothesis that musical abilities are inherent in every brain [93]. Even more important for a lifelong effect of music exposition are studies in which motor, sensory and cognitive abilities were examined in old age and classified according to whether the subjects had received music instruction in their youth for at least one year. Thus, it was confirmed that early stimulation of neuronal connections plays an essential role in maintaining cognitive abilities throughout lifetime. The longer the instruction took place, the less symmetrical and asymmetrical motor skills deteriorated [94].

About $1-2 \%$ of the human genome is assigned to the receptors of the olfaction and taste [95]. After the first trimester, the receptors of the olfactory organ in the upper nasal cavity are mature and connected to the brain by olfactory nerves $[95,96]$. The dendrites grow into the mucosa of the mouth and nose binding chemical substances; the 
signals are transmitted to the paleocortex and hippocampus [95]. Taste buds are scattered throughout the oral cavity from $12 \mathrm{SSW}$ onwards, mainly on the tongue and the front palate [97]. During the second trimester, sensory cells spread on the nasal septum and transmit hormonal responses through pheromones. During the third trimester the olfactory organ is mature. From 10 gestational weeks onwards, amniotic fluid with odorous substances from mother and child pass through the nasal cavity by fetal respiratory movements [98]. Aromatic substances of the maternal diet can thus already influence the chemosensory function. Rat fetuses react more strongly to odorous substances in the amniotic fluid than in the air, since the amniotic fluid intensifies the chemosensory reaction [99]. In sheep, intranasal injection of odorous substances causes changes in FHR [96]. In humans, the intra-amnial injection of sweet or bitter substances causes changes in swallowing [97].

Long-term memory of odors and flavors has been shown in newborns of alcoholic mothers by increased reactivity to odor over $48 \mathrm{~h}$ compared to other newborns [100] without differences in the reaction to lemon [101]. Newborns prefer to suck on a breast previously coated with amniotic fluid from their mothers [95]; if the amniotic fluid differed, the babies oriented towards the odor of their own mother, which suggests an olfactory memory [100]. The smell of amniotic fluid calms children, who then scream less [102]. Newborns orient to the smell of their mothers reacting with breathing or facial movements [103]. This suggests that odors support social bonding, which is used in incubators for premature babies by giving them a stuffed animal that the mother carried. A habituation effect was described for repeated exposure to odors [103]. Smell and taste experiences might have therapeutic consequences to stabilize breastfeeding, adaptation, and bonding, and can also represent an extended form of "enrichment".

\section{Implications for future projects}

Physical, mental, and social health is more than the absence of suffering but implies that people can unfold their genetic capabilities. Scientific projects help to link the fetal development with new insights of epigenetic processes and their significance for public health concepts. Exposure to adverse environments in early life, such as abnormal nutrition and maternal stress may reprogram organ development with potentially lifelong consequences and disrupt cellular functions contributing to accelerated aging and the potential risk of disease in older age [26].
Both animal and human data show that the uncontrollable impact of even ancestral adverse stress and trauma can potentially be offset by a beneficial experience throughout life [26].

Our motivation for designing creative projects was increased from a study showing that newborns of pregnant women with positive pregnancy experiences had increased telomere lengths, which may improve their chances of a longer life [104]. The bush fire in Alberta, Hurricane Harvey in Houston, and migrant family stress in Pforzheim were identified as study populations of vulnerable populations [12]. Creative writing of pregnant women has been used and shown that short episodes of expressive writing can improve cognitive outcome of the offspring $[105,106]$. In a review by Olson et al. [12] it is described that children will be later examined for neuromotor outcome, metabolic biomarkers, and the risk for a later premature birth.

A Canadian team tracked the children of pregnant women who were exposed to increased stress before or during pregnancy during the 1998 ice storm in Quebec ("Project Ice Storm"). Between the ages of 2 and 10 years, the stress experience explained differences in speech characteristics, especially at early exposure, increasing rates of obesity, autism, pro-inflammatory markers, and altered DNA methylation up to 15 years. Exposure of pregnant women to flooding in Iowa (US) and in Queensland (Australia) found similar effects on cognitive and motor development or even obesity rates in the offspring [12].

Currently, the outbreak of the coronavirus disease exposes pregnant women to increased risks and fears.

A systematic review found 3,166 papers on this topic and then included 24 studies reporting negative psychological effects such as post-traumatic stress symptoms, confusion, and anger. Stressors included longer quarantine duration, infection fears, frustration, boredom, inadequate supplies, or financial loss. Some researchers have suggested long-lasting effects [107]. It has been shown that the exposure to COVID-19, combined with quarantine measures adversely affected the thoughts and emotions of mothers, worsening her depressive symptoms [11].

This all means that the need for screening for anxiety, stress, and depression in pregnant women who - as pointed out - may transmit the negative consequences to following generations has even increased in the whole population and not only the described vulnerable subgroups.

Already in 2002, the first author of this article proposed the design of trials addressing not only the wish to study the influence of music on developing children but also the desire to create concepts of a caring relationship by musical interventions and thus to fulfill the concept of 
environmental, sensory and social enrichment. A variety of ideas how future interventions could be realized and evaluated was given, such as to evaluate parents' preferences, their wish to move or to sing and to perform these studies cross-culturally to evaluate further insights regarding anthropological perspectives. Simultaneously, it was proposed to focus on specific risk groups, to use questionnaires and biophysical methods to document instantaneous and long-term effects [108]. Thereafter, we have evaluated the musical behavior of mothers during pregnancy and proposed to compare intervention with control groups [109].

Unfortunately, as much as screening for genetic aberrations has been pushed forward and is combined with enormous costs but comparably only few options of therapy rather than pregnancy terminations, the screening for maternal characteristics that cause epigenetic diseases in the offspring which could be followed by preventive interventions are neglected.

Although the concept of the fetus as a patient demands that we have preventive ethical obligations not only for visible diseases but also for environments limiting potentials of healthy development and aging of the offspring, the most frequent reaction of obstetricians towards the importance of early interventions is rather characterized by "passive aggressive resistance" [110]. In contrast, it took only a noticeably short time to convince the Berlin Philharmonics and dedicated artists to help to create, design and realize acoustic enrichment programs for parents-tobe. Thus, we have the chance to offer concerts and workshops at two-week intervals from early pregnancy onwards within the Foyer of the Berlin Philharmonic chamber concert hall within a cohort and feasibility study and to evaluate psychological and biological consequences.

We needed time and perseverance to find and construct a research group of a satisfactory artistic and scientific level by integrating dedicated maternal-fetal medicine specialists, psychologists, epidemiologists, and artists. The initial common goal is to determine the compliance of parents-to be, and to compare results of an intervention group with a pre-existing cohort. Further goals are whether creative interventions can counteract the harmful effects of maternal stressors and then to focus on specific interventions in vulnerable subgroups. Finally, we have the vision, to demonstrate the "survival value" of musical and social interventions, to decrease inequality and to extend the concept to a cross-cultural movement.

Acknowledgments: The first author expresses her gratitude to those who have agreed to support the realization of the described project not compromising in their humanistic, scientific, and artistic visions. Such projects are now desperately needed. We thank Prof. Olson from Edmonton, Canada, for helpful and sensitive interest from the OPERA (OPtimal Environment Risk Assessment) group, Bettina Frei, head of the Berlin Philharmonic Educational Department and Raimar Orlovsky representing and organizing the musicians of the orchestra for being open to develop music programs and workshops to be performed for three years on Saturday mornings within the Foyer of the Berlin Philharmonic chamber music hall. Prof. Sonja Entringer from the Charité Berlin has already followed and evaluated biologic and psychologic markers in a Berlin cohort and Thorsten Braun is experienced in placental stress markers. They are both willing to cooperate by investing their clinical and laboratory skills. Clinicians from the Friedrichshain Vivantes hospital deliberately offered to help with non-invasive measurements of stress markers before and after the interventions. In advance, we thank Berlin midwives and colleagues who are happy to inform parents-to-be in the first trimester, e.g., in August and September 2021.

Research funding: None declared.

Author contributions: All authors have accepted responsibility for the entire content of this manuscript and approved its submission.

Competing interests: Authors state no conflict of interest. Informed consent: Not applicable.

Ethical approval: Not applicable.

\section{References}

1. Aristoteles. De generatione animalium 384-22;2,4. 738b25-35.

2. Prechtl HF. The behavioural states of the newborn infant (a review). Brain Res 1974;76:185-212.

3. Barker DJ, Gluckman PD, Godfrey KM, Harding JE, Owens JA, Robinson JS. Fetal nutrition and cardiovascular disease in adult life. Lancet 1993;341:938-41.

4. Barker DJ, Clark PM. Fetal undernutrition and disease in later life. Rev Reprod 1997;2:105-12.

5. Barker DJ, Eriksson JG, Forsen T, Osmond C. Fetal origins of adult disease: strength of effects and biological basis. Int J Epidemiol 2002;31:1235-9.

6. Van den Bergh BRH, van den Heuvel MI, Lahti M, Braeken M, de Rooij SR, Entringer S, et al. Prenatal developmental origins of behavior and mental health: the influence of maternal stress in pregnancy. Neurosci Biobehav Rev 2020;117:26-64.

7. Entringer S. Prenatal stress exposure and fetal programming of complex phenotypes: interactive effects with multiple risk factors. Neurosci Biobehav Rev 2020;117:3-4.

8. Bergman K, Sarkar P, O’Connor TG, Modi N, Glover V. Maternal stress during pregnancy predicts cognitive ability and fearfulness in infancy. J Am Acad Child Adolesc Psychiatry 2007;46:1454-63. 
9. Baor L, Soskolne V. Mothers of IVF and spontaneously conceived twins: a comparison of prenatal maternal expectations, coping resources and maternal stress. Hum Reprod 2010;25:1490-6.

10. Wu Y, Kapse K, Jacobs M, Niforatos-Andescavage N, Donofrio MT, Krishnan A, et al. Association of maternal psychological distress with in utero brain development in fetuses with congenital heart disease. JAMA Pediatr 2020;174:e195316.

11. Zanardo V, Manghina V, Giliberti L, Vettore M, Severino L, Straface G. Psychological impact of COVID-19 quarantine measures in northeastern Italy on mothers in the immediate postpartum period. Int J Gynaecol Obstet 2020;150:184-8.

12. Olson DM, Bremault-Phillips S, King S, Metz GAS, Montesanti S, Olson JK, et al. Recent Canadian efforts to develop population-level pregnancy intervention studies to mitigate effects of natural disasters and other tragedies. J Dev Origins Health Dis 2019;10:108-14.

13. Rosenzweig MR, Bennett EL. Psychobiology of plasticity: effects of training and experience on brain and behavior. Behav Brain Res 1996;78:57-65.

14. O'Donnell KJ, Meaney MJ. Fetal origins of mental health: the developmental origins of health and disease hypothesis. Am J Psychiatry 2017;174:319-28.

15. Black MM, Walker SP, Fernald LCH, Andersen CT, DiGirolamo AM, Lu C, et al. Early childhood development coming of age: science through the life course. Lancet 2017;389:77-90.

16. Boersma G, Tamashiro KL. Individual differences in the effects of prenatal stress exposure in rodents. Neurobiology 2015;1:100-8.

17. Dipietro JA. Maternal stress in pregnancy: considerations for fetal development. J Adolesc Health 2012;51(2 Suppl):S3-8.

18. Van Damme R, Van Parys AS, Vogels C, Roelens K, Lemmens GMD. A mental health care protocol for the screening, detection and treatment of perinatal anxiety and depressive disorders in Flanders. J Psychosom Res 2020;128:109865.

19. Huizink AC, Menting B, De Moor MHM, Verhage ML, Kunseler FC, Schuengel C, et al. From prenatal anxiety to parenting stress: a longitudinal study. Arch Wom Ment Health 2017;20: 663-72.

20. Puterman E, Lin J, Krauss J, Blackburn EH, Epel ES. Determinants of telomere attrition over 1 year in healthy older women: stress and health behaviors matter. Mol Psychiatry 2015;20:529-35.

21. Lazarides C, Epel ES, Lin J, Blackburn EH, Voelkle MC, Buss C, et al. Maternal pro-inflammatory state during pregnancy and newborn leukocyte telomere length: a prospective investigation. Brain Behav Immun 2019;80:419-26.

22. Faraji J, Singh S, Soltanpour N, Sutherland RJ, Metz GAS. Environmental determinants of behavioural responses to shortterm stress in rats: evidence for inhibitory effect of ambient landmarks. Behav Brain Res 2020;379:112332.

23. Grant KA, Sandman CA, Wing DA, Dmitrieva J, Davis EP. Prenatal programming of postnatal susceptibility to memory impairments: a developmental double jeopardy. Psychol Sci 2015;26:1054-62.

24. Wu Y, Lu YC, Jacobs M, Pradhan S, Kapse K, Zhao L, et al. Association of prenatal maternal psychological distress with fetal brain growth, metabolism, and cortical maturation. JAMA Netw Open 2020;3:e1919940.

25. Poplawski J, Radmilovic A, Montina TD, Metz GAS. Cardiorenal metabolic biomarkers link early life stress to risk of noncommunicable diseases and adverse mental health outcomes. Sci Rep 2020;10:13295.
26. Ambeskovic M, Roseboom TJ, Metz GAS. Transgenerational effects of early environmental insults on aging and disease incidence. Neurosci Biobehav Rev 2020;117:297-316.

27. Rakers F, Rupprecht S, Dreiling M, Bergmeier C, Witte OW, Schwab M. Transfer of maternal psychosocial stress to the fetus. Neurosci Biobehav Rev 2017;22:S0149-7634-9.

28. Pluess M, Belsky J. Prenatal programming of postnatal plasticity? Dev Psychopathol 2011;23:29-38.

29. Boyce WT, Ellis BJ. Biological sensitivity to context: I. An evolutionary-developmental theory of the origins and functions of stress reactivity. Dev Psychopathol 2005;17:271-301.

30. Rikkonen K, Pesonen AK, Heinonen K, Lahti J, Kajantie E, Forsen T, et al. Infant growth and hostility in adult life. Psychosom Med 2008;70:306-13.

31. Roseboom TJ, Painter RC, van Abeelen AF, Veenendaal MV, de Rooij SR. Hungry in the womb: what are the consequences? Lessons from the Dutch famine. Maturitas 2011;70:141-5.

32. Bohnert KM, Breslau N. Stability of psychiatric outcomes of low birth weight: a longitudinal investigation. Arch Gen Psychiatry 2008;65:1080-6.

33. Tully LA, Arseneault L, Caspi A, Moffitt TE, Morgan J. Does maternal warmth moderate the effects of birth weight on twins' attention-deficit/hyperactivity disorder (ADHD) symptoms and low IQ? J Consult Clin Psychol 2004;72:218-26.

34. Buss C, Entringer S, Wadhwa PD. Fetal programming of brain development: intrauterine stress and susceptibility to psychopathology. Sci Signal 2012;5:pt7.

35. Kelly RH, Russo J, Holt VL, Danielsen BH, Zatzick DF, Walker E, et al. Psychiatric and substance use disorders as risk factors for low birth weight and preterm delivery. Obstet Gynecol 2002;100: 297-304.

36. Straub N, Grunert P, Northstone K, Emmett P. Economic impact of breast-feeding-associated improvements of childhood cognitive development, based on data from the ALSPAC. Br J Nutr 2019;122: S16-21.

37. Blair C. Early intervention for low birth weight, preterm infants: the role of negative emotionality in the specification of effects. Dev Psychopathol 2002;14:311-32.

38. Smits L, Krabbendam L, de Bie R, Essed G, van Os J. Lower birth weight of Dutch neonates who were in utero at the time of the $9 / 11$ attacks. J Psychosom Res 2006;61:715-7.

39. Khashan AS, McNamee R, Abel KM, Pedersen MG, Webb RT, Kenny LC, et al. Reduced infant birthweight consequent upon maternal exposure to severe life events. Psychosom Med 2008; 70:688-94

40. Hartwig IR, Pincus MK, Diemert A, Hecher K, Arck PC. Sex-specific effect of first-trimester maternal progesterone on birthweight. Hum Reprod 2013;28:77-86.

41. Hebb DO. The effects of early experience on problem solving at maturity. Am Psychol 1947;2:306-7.

42. Fares RP, Belmeguenai A, Sanchez PE, Kouchi HY, Bodennec J, Morales A, et al. Standardized environmental enrichment supports enhanced brain plasticity in healthy rats and prevents cognitive impairment in epileptic rats. PloS One 2013; 8:e53888.

43. Baroncelli L, Braschi C, Spolidoro M, Begenisic T, Sale A, Maffei L. Nurturing brain plasticity: impact of environmental enrichment. Cell Death Differ 2010;17:1092-103. 
44. Jung CK, Herms J. Structural dynamics of dendritic spines are influenced by an environmental enrichment: an in vivo imaging study. Cerebr Cortex 2014;24:377-84.

45. Falkenberg T, Mohammed AK, Henriksson B, Persson H, Winblad $B$, Lindefors $N$. Increased expression of brain-derived neurotrophic factor mRNA in rat hippocampus is associated with improved spatial memory and enriched environment. Neurosci Lett 1992;138:153-6.

46. Kempermann G, Kuhn HG, Gage FH. More hippocampal neurons in adult mice living in an enriched environment. Nature 1997;386: 493-5.

47. Bennett EL, Diamond MC, Krech D, Rosenzweig MR. Chemical and anatomical plasticity brain. Science 1964;146:610-9.

48. van Praag H, Kempermann G, Gage FH. Neural consequences of environmental enrichment. Nat Rev Neurosci 2000;1:191-8.

49. Sale A, Berardi N, Maffei L. Enrich the environment to empower the brain. Trends Neurosci 2009;32:233-9.

50. Sale A, Cenni MC, Ciucci F, Putignano E, Chierzi S, Maffei L. Maternal enrichment during pregnancy accelerates retinal development of the fetus. PloS One 2007;2:e1160.

51. Maruoka T, Kodomari I, Yamauchi R, Wada E, Wada K. Maternal enrichment affects prenatal hippocampal proliferation and openfield behaviors in female offspring mice. Neurosci Lett 2009;454: 28-32.

52. Cancedda L, Putignano E, Sale A, Viegi A, Berardi N, Maffei L. Acceleration of visual system development by environmental enrichment. J Neurosci 2004;24:4840-8.

53. Cardenas L, Garcia-Garcia F, Santiago-Roque I, Martinez AJ, CoriaAvila GA, Corona-Morales AA. Enriched environment restricted to gestation accelerates the development of sensory and motor circuits in the rat pup. Int J Dev Neurosci 2015;41:68-73.

54. Mychasiuk R, Harker A, Ilnytskyy S, Gibb R. Paternal stress prior to conception alters DNA methylation and behaviour of developing rat offspring. Neuroscience 2013;241:100-5.

55. Mueller BR, Bale TL. Sex-specific programming of offspring emotionality after stress early in pregnancy. J Neurosci 2008;28: 9055-65.

56. Zucchi FC, Yao Y, Metz GA. The secret language of destiny: stress imprinting and transgenerational origins of disease. Front Genet 2012;3:96.

57. Babenko 0, Kovalchuk I, Metz GA. Stress-induced perinatal and transgenerational epigenetic programming of brain development and mental health. Neurosci Biobehav Rev 2015; 48:70-91.

58. McCreary JK, Erickson ZT, Hao Y, Ilnytskyy Y, Kovalchuk I, Metz GA. Environmental intervention as a therapy for adverse programming by ancestral stress. Sci Rep 2016;6:37814.

59. McCreary JK, Erickson ZT, Metz GA. Environmental enrichment mitigates the impact of ancestral stress on motor skill and corticospinal tract plasticity. Neurosci Lett 2016;632:181-6.

60. Karatsoreos IN, McEwen BS. Psychobiological allostasis: resistance, resilience and vulnerability. Trends Cogn Sci 2011;15: 576-84.

61. Ambeskovic M, Ilnytskyy Y, Kiss D, Currie C, Montina T, Kovalchuk I, et al. Ancestral stress programs sex-specific biological aging trajectories and non-communicable disease risk. Aging (Albany NY) 2020;12:3828-47.

62. Faraji J, Karimi M, Soltanpour N, Moharrerie A, Rouhzadeh Z, Lotfi $\mathrm{H}$, et al. Oxytocin-mediated social enrichment promotes longer telomeres and novelty seeking. Elife 2018;7. https://doi. org/10.7554/eLife.40262.

63. Arabin B, Jahn M. The development of senses. In: FAEA C, editor. Current progress in obstetrics and gynaecology 4. Mumbai: Kothari Medical Subscription Services Pvt. Ltd.; 2017.

64. Hooker D. The prenatal origin of behavior. Kansas: University of Kansas Press; 1952.

65. Anand KJ, Hickey PR. Pain and its effects in the human neonate and fetus. N Engl J Med 1987;317:1321-9.

66. Teixeira J, Fogliani R, Giannakoulopoulos X, Glover V, Fisk NM. Fetal haemodynamic stress response to invasive procedures. Lancet 1996;347:624.

67. Giannakoulopoulos X, Teixeira J, Fisk N, Glover V. Human fetal and maternal noradrenaline responses to invasive procedures. Pediatr Res 1999;45:494-9.

68. Arabin B, Bos R, Rijlaarsdam R, Mohnhaupt A, van Eyck J. The onset of inter-human contacts: longitudinal ultrasound observations in early twin pregnancies. Ultrasound Obstet Gynecol 1996;8:166-73.

69. Knickmeyer R, Baron-Cohen S, Raggatt P, Taylor K, Hackett G. Fetal testosterone and empathy. Horm Behav 2006;49:282-92.

70. Klimach VJ, Cooke RW. Maturation of the neonatal somatosensory evoked response in preterm infants. Dev Med Child Neurol 1988;30:208-14.

71. Edelman GM. Biochemistry and the sciences of recognition. J Biol Chem 2004;279:7361-9.

72. Charpak N, Ruiz-Pelaez JG, Figueroa de CZ, Charpak Y. A randomized, controlled trial of kangaroo mother care: results of follow-up at 1 year of corrected age. Pediatrics 2001;108: 1072-9.

73. Hepper PG, Shahidullah BS. Development of fetal hearing. Arch Dis Child 1994;71:F81-7.

74. Blum T, Saling E, Bauer R. First magnetoencephalographic recordings of the brain activity of a human fetus. $\mathrm{Br} J$ Obstet Gynaecol 1985;92:1224-9.

75. Devoe LD, Murray C, Faircloth D, Ramos E. Vibroacoustic stimulation and fetal behavioral state in normal term human pregnancy. Am J Obstet Gynecol 1990;163:1156-61.

76. van Heteren CF, Boekkooi PF, Jongsma HW, Nijhuis JG. Fetal learning and memory. Lancet 2000;356:1169-70.

77. Querleu D, Renard X, Boutteville C, Crepin G. Hearing by the human fetus? Semin Perinatol 1989;13:409-20.

78. DeCasper AJ, Lecanuet J-P, Busnel M-C, Granier-Deferre C, Maugeais R. Fetal reactions to recurrent maternal speech. Infant Behav Dev 1994;17:159-64.

79. DeCasper AJ, Fifer WP. Of human bonding: newborns prefer their mothers' voices. Science 1980;208:1174-6.

80. Woodward SC, Guidozzi F. Intrauterine rhythm and blues? $\mathrm{Br} J$ Obstet Gynaecol 1992;99:787-9.

81. DeCasper AJ, Sigafoos AD. The intrauterine heartbeat: a potent reinforcer for newborns. Infant Behav Dev 1983;6:19-25.

82. Zimmer EZ, Divon MY, Vilensky AF, Sarna ZF, Peretz BA, Paldi E. Maternal exposure to music and fetal activity. Eur J Obstet Gynecol Reprod Biol 1982;13:209-13.

83. Cheng D, Huang Y, Qi G. Influence of prenatal music-and touch enrichment on the IQ, motor development and behavior of infants. Chin J Psychol 1994;8:148-51.

84. Lamont A, Dibben N. Motivic structure and the perception of similarity. Music Percept 2001;18:245-74. 
85. Cheour M, Ceponiene R, Leppanen P, Alho K, Kujala T, Renlund M, et al. The auditory sensory memory trace decays rapidly in newborns. Scand J Psychol 2002;43:33-9.

86. Roederer JG. The search for a survival value of music. Music Percept 1984:350-6. https://doi.org/10.2307/40285265.

87. Fifer WP, Moon CM. The role of mother's voice in the organization of brain function in the newborn. Acta Paediatr 1994;397:86-93.

88. Condon WS, Sander LW. Neonate movement is synchronized with adult speech: interactional participation and language acquisition. Science 1974;183:99-101.

89. Truby HM. Prenatal and neonatal speech, pre-speech and an infantile speech lexicon. Child Lang 1975;27:1-3.

90. Jahn M, Muller-Mazzotta J, Arabin B. Music devices for the fetus? An evaluation of pregnancy music belts. J Perinat Med 2016;44:637-43.

91. Lubetzky R, Mimouni FB, Dollberg S, Reifen R, Ashbel G, Mandel $D$. Effect of music by Mozart on energy expenditure in growing preterm infants. Pediatrics 2010;125:e24-8.

92. Aldridge DGG, Neugebauer L. A pilot study of music therapy in the treatment of children with developmental delay. Complement Ther Med 1995:197-205. https://doi.org/10.1016/s0965-2299(95) 80072-7.

93. Koelsch S. Toward a neural basis of music perception: a review and updated model. Front Psychol 2011;2:110.

94. Metzler MJ, Saucier DM, Metz GA. Enriched childhood experiences moderate age-related motor and cognitive decline. Front Behav Neurosci 2013;7:1.

95. Winberg J, Porter RH. Olfaction and human neonatal behaviour: clinical implications. Acta Paediatr 1998;87:6-10.

96. Beauchamp GMJ. Sensitive periods in the development of human flavor perception and preference. Ann Nestle 1998;56:19-31.

97. Lecanuet JP, Schaal B. Fetal sensory competencies. Eur J Obstet Gynecol Reprod Biol 1996;68:1-23.

98. Schaal B, Hummel T, Soussignan R. Olfaction in the fetal and premature infant: functional status and clinical implications. Clin Perinatol 2004;31:261-85.vi-vii.

99. Smotherman WP, Robinson SR. Rat fetuses respond to chemical stimuli in gas phase. Physiol Behav 1990;47:863-8.
100. Schaal B, Marlier L, Soussignan R. Olfactory function in the human fetus: evidence from selective neonatal responsiveness to the odor of amniotic fluid. Behav Neurosci 1998;112:1438-49.

101. Faas AE, Sponton ED, Moya PR, Molina JC. Differential responsiveness to alcohol odor in human neonates: effects of maternal consumption during gestation. Alcohol 2000;22: 7-17.

102. Garcia AP, White-Traut R. Preterm infants' responses to taste/ smell and tactile stimulation during an apneic episode. J Pediatr Nurs 1993;8:245-52.

103. Durand K, Baudouin JY, Lewkowicz DJ, Goubet N, Schaal B. Eyecatching odors: olfaction elicits sustained gazing to faces and eyes in 4-month-old infants. PLoS One 2013;8:e70677.

104. Verner G, Epel E, Lahti-Pulkkinen M, Kajantie E, Buss C, Lin J, et al. Maternal psychological resilience during pregnancy and fetal cellular aging. Psychoneuroendocrinology 2019;107:35.

105. Pennebaker JW. Expressive writing in psychological science. Perspect Psychol Sci 2018;13:226-9.

106. Pennebaker JW, Kiecolt-Glaser JK, Glaser R. Confronting traumatic experience and immunocompetence: a reply to Neale, Cox, Valdimarsdottir, and stone. J Consult Clin Psychol 1988;56: 638-9.

107. Brooks SK, Webster RK, Smith LE, Woodland L, Wessely S, Greenberg N, et al. The psychological impact of quarantine and how to reduce it: rapid review of the evidence. Lancet 2020;395: 912-20.

108. Arabin B. Music during pregnancy. Ultrasound Obstet Gynecol 2002;20:425-30.

109. Arabin B, Jahn M. Need for interventional studies on the impact of music in the perinatal period: results of a pilot study on women's preferences and review of the literature. J Matern Fetal Neonatal Med 2013;26:357-62.

110. Chervenak FA, McCullough LB. Ethical dimensions of the fetus as a patient. Best Pract Res Clin Obstet Gynaecol 2017;43:2-9.

111. McCreary JK, Metz GAS. Environmental enrichment as an intervention for adverse health outcomes of prenatal stress. Environ Epigenet 2016;2:dvw013. 